\title{
Oferecendo Ciência no Espaço: A Eva Pós-Gutenberg
}

$\mathbf{E}^{n}$ NTRE 27 e 30 DE AgOSTO PASSADO, graças ao patrocínio da diretoria nacional da SBEM, tive a oportunidade de atender, no Rio de Janeiro, ao IFSE-10, Tenth International Conference of Science Editors. Esta edição 2000 , denominada IFSE-Rio Conference, foi organizada por um conjunto de entidades nacionais e internacionais, dentre as quais se destacam: a IFSE (International Federation of Science Editors), a ABEC (Associação Brasileira de Editores Científicos), a BIREME-PAHO-WHO (pela Latin American and Caribbean Center on Health Sciences Information) e a ABC (Academia Brasileira de Ciências), contando com o apoio e patrocínio do CNPq, FAPESP, FINEP, FAPERJ, CAPES, LNCC e FIOCRUZ.

Dificil sintetizar num texto restrito tamanha gama de tópicos e divergência de opiniōes e posturas quanto a temas tão em moda mas ainda tão polêmicos, como: "Comunicação e disseminação da ciência", "Utilidade e valor das revistas científicas no passado no presente e no futuro", "O poder da informação interligada", "Arquivamento aberto para uma sociedade aberta: liberando a literatura erudita e científica online através do auto-arquivamento público", "Ciência invisível: onde a comunicação científica está falhando?", "Comunicando ciência: o diálogo entre ciência, mídia e sociedade", "Porquê e para quem os países em desenvolvimento estão publicando revistas científicas?", "Acesso livre e peer review aberto: de mãos dadas em direção a um futuro melhor", entre outros tantos.

Participaram como simposistas, entre outros: Ellis Rubinstein (editor, Science), Carol Tenopir (University of Tennessee), Frank Gannon (diretor, EMBO - European Molecular Biology Organization), Stevan Harnad (University of Southampton, UK), W. Wayt Gibbs (Scientific American), Barbara Kirsop (Bioline Publications), Nancy K. Bayers e James Testa (ISI - Institute for Scientific Information), Lewis J. Greene (Brazilian Journal of Medical and Biological Research), Abel Packer e Regina Figueiredo Castro (Latin American and Caribbean Center on Health Sciences Information, BIREME/PAHO/WHO), Steve Fuller (University of Warwick), Fiona Godlee (BioMed Central), Michael A. Keller (HighWire Press) e Leslic Chan (Bioline International)

Defensores de algumas publicações eletrônicas são enfáticos: "Free science to everyone, without any limitations" (Ciência livre para todos, sem quaisquer limitações). Esta posição é defendida em especial quando se argumenta que as grandes editoras científicas (americanas e européias) aproveitam-se (apropriam-se, na verdade), como intermediadoras, dos conhecimentos gerados pelos cientistas, que almejam torná-las públicas e visíveis, não somente não recebendo nada $\mathrm{em}$ troca, como habitualmente tendo que pagar (e cada vez mais) para divulgá-las, c os usuários, o imenso público leitor, ávido por conhecimento novo e atualizado. Para as grandes editoras existe um imenso mercado de ambos os lados, os autores e os leitores. Ganha (financeiramente) quem explora o aspecto comercial, ficando a ciência muitas vezes num plano secundário, como atesta a abundância de publicações estrangeiras que năo têm o menor sentido, $\mathrm{cm}$
Claudio E. Kater

Editor-chefe, $A B E \mathcal{O} M$ 
contraposição com as clássicas e sempre respeitadas "Science", "Nature" e "New England Journal of Medicine", para ficar apenas nas mais tradicionais, na nossa área de interesse.

Por outro lado, defensores das revistas científicas impressas tradicionais, denominadas pelos seus críticos tavez até um pouco pejorativamente - de revistas eruditas ("scholarly journals"), parecem procurar desesperadamente desmistificar os seguintes argumentos de seus oponentes: (1) "revistas eruditas clássicas não são lidas"; (2) "existe um número muito grande de revistas"; (3) "revistas são somente para os autores, não para os leitores"; (4) "os cientistas já conhecem as informações muito antes delas serem impressas"; e (5) "as revistas eletrônicas irão, muito em breve, substituir as impressas".

Um ponto interessante abordado foi o uso (aparentemente indevido) do chamado "fator de impacto" das revistas médicas em benefício pessoal. Quando definitu o termo e sua aplicação, Garfield ("How can impact factors be impoved". Br Med J 1966;313:4135) escreveu o seguinte: “... enfatizar que o valor potencial dos fatores de impacto deve ser primariamente voltado para o manuseio e gerenciamento das coleçōes de revistas nas bibliotecas". Entretanto, parece que os objetivos primordiais de parte dos cientistas estão sendo distorcidos do propósito original do esforço da pesquisa científica em si para a tentativa de atingir maiores índices de citação, especialmente nas ciências biomédicas. Com o intuito de obter (ou manter) os beneficios do suporte financeiro e da promoção acadêmica, a maioria dos cientistas na área médica tem preferido trabalhar mais no campo da genética molecular do que em participar de pesquisas clínicas aplicadas visando o paciente. Muitas revistas científicas de qualidade têm, também, contribuído para reforçar esta distorçăo, passando apenas a aceitar trabalhos que enfoquem exclusivamente a biologia molecular. Este fato parece estar contribuindo para uma redução significativa de pesquisas voltadas para a saúde e para o bem estar do paciente. Além disso, "fatores de impacto" e "indices de citação" (quaisquer que sejam eles) aparentemente não medem ou refletem com precisão: (1) a qualidade de um artigo individual, (2) sua importância clínica, (3) sua influência na política pública de saúde, (4) seu eventual interesse local ou regional. Assim, conclui-se que nenhum método isolado de aferição de uma revista (ou de um autor) é suficiente para indicar sua qualidade ou utilidade!

Outro aspecto que merece discussão é o da revisão prévia de um determinado trabalho científico, antes de sua divulgação, pelos pares ("peer review system") e posterior validação da pesquisa e do texto. No momento encontramo-nos numa encruzilhada que não satisfaz a nenhum dos dois lados: os "autores", que querem divulgação ampla de seu trabalho (mas também desejam um "selo de aprovaçăo" e salvar as aparências), e os "usuários", que querem acesso irrestrito à informação (mas também desejam "garantia de qualidade" c melhor seleção e colocação no contexto). Merece atenção a abordagem do editor do Brazilian Journal of Medical and Biomedical Research, Lewis Greene, sobre as funções especiais das revistas científicas nos países em desenvolvimento: (1) papel educacional no processo de revisão por pares ("peer review"), objetivando treinar revisores em análise crítica e treinar autores para escrever artigos de maneira clara; (2) consolidar áreas de pesquisa; e (3) importância das revistas regionais como fonte para a publicação de dados relevantes para a sociedade, a comunidade de pesquisadores, e para o próprio governo da região, além de servir de receptáculo para a publicação de artigos rejeitados pelas revistas de primeira linha.

Estes são apenas alguns dos tópicos que me pareceram importantes e que merecem de nossa parte alguma consideração para que possamos definir caminhos e seguir na direção mais acertada quando da eventual colocação de nossos "Arquivos" na Internet.

A seguir, divulgo alguns sites (URLS) que contêm informações e referências a publicações, onde os leitores poderão encontrar material farto e variado para seu entretenimento e cultura científica. Tenham uma boa navegação!:

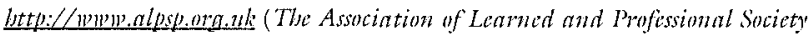
Publishore enfoca aspectos e problemas comuns do sistema cudito de publicação: copyright, licenciamento, autoria, novas tecnologias, bibliotecas, per rovicw, metadata, marketing)

bttp://mw!w, arXiv, mp bttp://nwm.eprints.ura

bttp://wwm.openardipesorg (Stevan Harnad promovendo a abcrtum de publicaçós e revistas médicas de forma live c irrestrita para o público) bttp://mwu.bioline. Udt.org.tro (Bioline International: acesso eletronico de baixo custo para revistas de pesquisa em biociencias de qualidade, provenientes de países en desenvolvimento: Africa, 13 asil, Cuba, India, Indoncisia)

bttp://mm Gionedcentral.com

bttp://mww biveme br (BIREME - Online: acesso livece gratuito ao Medline, Lilacs c outras importantes bases de dados especializadas)

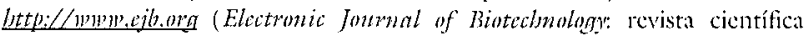
internacional com "per reviow", editada cxclusivamente cm formato eletronico, com publicaçào e distribuiçào gratuitas)

bttp://mmw. froonedicaliommals

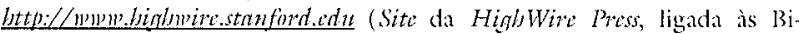
bliotecas da Universidade de Stanford) bttp://wwp.isinet.com (ISI - Institute for Sciontific Information)

bttp://mwp.pulmedcentral.nilh.gov! (Projeto pionciro do Dr. Varmus de publicar revistas cientiticas de forma eletrônica)

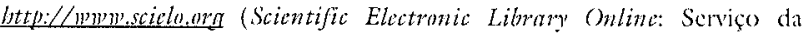
BIREME con apoio da FAPESP, caracterizado como tum Modelo multilingua para publicaçào eletrônica cooperativa de revistas científicas nos países em desenvolvimento) 